\title{
EVIDENCE FOR ACTION
}

\section{Accountability for quality of care: Monitoring all aspects of quality across a}

framework adapted for action

Louise Hulton ${ }^{\mathrm{a}, \mathrm{b}}$, Zoe Matthews ${ }^{\mathrm{c}}$, Sarah Bandali ${ }^{\mathrm{a}, \mathrm{b}}$, Abubakar Izge ${ }^{\mathrm{b}}$, Ramatu Daroda $^{\text {b }}$, William Stones ${ }^{\mathrm{d}, \mathrm{e},{ }^{*}}$

${ }^{a}$ Evidence for Action, Options Consultancy Services, London, UK

${ }^{\mathrm{b}}$ Maternal, Newborn and Child Health Programme (MNCH2), Northern Nigeria

${ }^{c}$ Department of Social Statistics and Demography, University of Southampton, Southampton, UK

d School of Medicine, University of St Andrews, St Andrews, UK

e Departments of Obstetrics and Gynecology and Public Health, College of Medicine, University of Malawi, Blantyre, Malawi

${ }^{*}$ Corresponding author: William Stones

Medical and Biological Sciences Building, University of St Andrews, North Haugh, St Andrews, Fife, KY16 9TF, UK. Tel.: +44 1334463 619; fax: +44 1334467470.

Email address: rws6@st-andrews.ac.uk; wstones@medcol.mw

Keywords: Accountability; Maternal health; Neonatal health: Quality of Care

Synopsis: A multidimensional framework provides an index for measuring quality of maternity services. Certification based on such a framework can be used to improve quality and reward good performance. 


\section{Abstract}

Quality of care is essential to maternal and newborn survival. The multidimensional nature of quality of care means that frameworks are useful for capturing it. The present paper proposes an adaptation to a widely used quality of care framework for maternity services. The framework subdivides quality into two inter-related dimensions_-provision and experience of care-but suggests adaptations to reflect changes in the concept of quality over the past 15 years. The application of the updated framework is presented in a case study, which uses it to measure and inform quality improvements in northern Nigeria across the reproductive, maternal, newborn, and child health continuum of care. Data from 231 sampled basic and comprehensive emergency obstetric and newborn care (BEmONC and CEmONC) facilities in six northern Nigerian states showed that only $35 \%-47 \%$ of facilities met minimum quality standards in infrastructure. Standards for human resources performed better with $49 \%-73 \%$ reaching minimum standards. A framework like this could form the basis for a certification scheme. Certification offers a practical and concrete opportunity to drive quality standards up and reward good performance. It also offers a mechanism to strengthen accountability. 


\section{Introduction}

Efforts toward lowering maternal and newborn mortality in countries where levels are high have focused on introducing essential interventions before, during, and after childbirth for millions of women and their babies. However, the one reason why progress has fallen short of expectations is the quality of care (QoC) associated with the implementation of these key interventions [1]. Quality care can be thought of as "care which is effective, safe and a good experience for the patient" [2]. The WHO defines it as "the extent to which healthcare services provided to individuals and patient populations improve desired health outcomes. To achieve this, health care needs to be safe, effective, timely, efficient, equitable, and people-centered" [3, p2].

QoC is important to improving maternal and newborn health (MNH) [4]. However, the mere existence of $\mathrm{MNH}$ services offering essential interventions does not guarantee their use by women, nor does the use of those services guarantee optimal outcomes. Poor QoC has been highlighted as a key factor to explain why women either do not access services at all, access them late, or suffer avoidable adverse outcomes despite timely presentation [5]. The barriers to instituting QoC are complex and are often linked to insufficient monitoring to inform appropriate responses. Strong accountability mechanisms are also lacking to ensure that QoC data inform better practices and care.

While there has been substantial progress toward the Millennium Development Goal (MDG) for child survival in many countries, especially in the postneonatal age groups, MNH has proved more problematic. As we embark on the era of the successor Sustainable Development Goals (SDGs), and collectively build the new 
UN accountability framework toward 2030 , provision of care shown to meet quality standards will be necessary. Civil society commentators have pointed to the need to hold political decision-makers and public health officials accountable not only for availability of health care but also for investment in its quality and meaningful assessment of that quality [6].

The present paper reflects on a widely used QoC framework that was published in 2000 [7], and proposes an adaptation that improves its utility and reflects changes in the concept of quality over the past 15 years. Modifications to the concept of quality care have increasingly recognized the importance of transparent information, functional referral chains, and the importance of applying a framework to a whole system-not just individual facilities or services. Concerted efforts have also focused on capturing QoC from a client's perspective to complement measurements on the technical quality of services delivered. A case study that uses the updated framework to measure and inform quality improvements in Northern Nigeria is presented, including data and indicators for enhancing quality standards across the reproductive, maternal, newborn, and child health $(\mathrm{RMNCH})$ continuum of care in six states in Nigeria.

\section{Quality of care frameworks and their use to improve standards}

The notion of QoC is multidimensional [3]. As such, several frameworks have been developed to operationalize its key dimensions. Examples include the Donabedian model, which conceptualized QoC according to three dimensions: (1) "structure" referring to the settings where care is delivered; (2) "process" referring to whether or not what is known to be "good" medical care has been provided; and (3) "outcomes" 
referring to the impact of care on health [8]. The Organisation for Economic Cooperation and Development (OECD) also proposes a multidimensional framework consisting of effectiveness, safety, and responsiveness/patient centeredness [9].

Monitoring of quality in maternity services is not new. The "process indicators" established by the UN agencies in 1997 have stimulated the collection of facilitybased information on signal functions for a range of countries [10,11]. Information however on clients' perception and experience, which can contribute to poor uptake of health services, has not been routinely collected. Even if technical quality improvements are operationalized at facility level, poor provider attitudes and disrespectful interpersonal client-provider relations can still prevail. The White Ribbon Alliance's "Charter for respectful care" has highlighted substandard care and human rights abuses in facilities all over the world and relevant indicators are being developed [12]. The midwifery community has also recently asserted the importance of midwifery skills, both clinical and interpersonal, as part of quality care-and their new "quality care maternity framework" emphasizes respect, communication, promoting normal birthing processes, preventing complications, and using interventions only when needed [13].

Two recent reviews of successful health systems strengthening efforts across a number of countries have identified that systematic actions to strengthen QoC have been implemented only very recently [14]. Even where they have been implemented many of these initiatives fail to encapsulate all of the necessary dimensions of quality care-including the provision and experience of care—under one framework that lends itself to transparent monitoring efforts. 
In 2000, Hulton et al. [7] published a QoC framework for maternity services, which brought together key elements of quality. This framework subdivided quality into two interlinked dimensions and 10 important, comprehensive, and measurable elements of care (Figure 1). The first dimension relates to "provision of care" including the quality of the human, infrastructural, and information systems and clinical appropriateness of care. The second dimension, "experience of care" refers explicitly to the relationship that women and their families had with health services. The research that underpinned this framework demonstrated the importance not only of respect and dignity on health outcomes, but also of equity, availability, accessibility, and acceptability of care. The integration of the experience of care as a core dimension of quality recognized the interconnectedness of these two components of care explicitly. Women will not benefit optimally from high-quality clinical care if they are unable to access it when needed, are unable to afford it, and feel humiliated and unable to communicate what may be clinically essential information. As a result, poor perception and experience of care could result in life-threatening delays.

This framework was applied in the first decade of the millennium in urban India [15]. In Nepal it was adapted for use by the Ministry of Health to support quality assurance of safe motherhood services [16], and more recently it has been used to inform a recently endorsed WHO framework for QoC based on the structural components of a health system, summarized in Box 1. An adapted version of the framework, introduced later in the present paper, is being used in Northern Nigeria to guide the design and implementation of QoC activities (see case study below). 
Figure 1 shows the original QoC framework published in 2000 alongside the adaptions introduced to improve its utility and to reflect the broadening concept of quality over the past 15 years. There is a growing recognition that accountability has a role to play in quality improvement following the 2010 Commission for Information and Accountability recommendations [17]. Reflecting the increasing emphasis in international discourse on accountability as a way to drive up quality [17], there now exists an expanded understanding of evidence and information as being key to quality improvement. Previously there was an understanding of the need for wellkept maternity information in facilities, for example the use of birth registries and mortality reporting. However, there is now recognition that for realistic progress toward quality, providers need not only to collect good information about those who use their services, but also to communicate that data to the public and to provide information to facilitate health choices including, crucially, an appropriate level of information about achievement of defined quality standards, services available, and fees. This constitutes an important part of the experience of care-allowing women and their families to access well-communicated evidence and information in order to make decisions and to understand that quality care should be available to them.

The original framework grouped human and physical resources into one element. Over the past 15 years the disciplines that make up core pillars of a health system have developed [18] and this is reflected in the updated framework that breaks this element into three: human resources, infrastructure and equipment, and supplies. The original framework separated "internationally recognized good practice" and "use of appropriate technologies and management of emergencies." These three elements are now incorporated into one overarching element—good clinical 
practice-and are linked more explicitly with the dimension of referral and networks of care.

Unlike earlier frameworks that only considered referral from one facility to another, our framework now supports the monitoring of a fully integrated service that can examine referral between and within different services and facilities (e.g. family planning with well-baby care) as well. This element-referral and networks of careallows for assessing and supporting quality improvement across the continuum of care both horizontally in terms of progression through pregnancy, birth, and newborn/postpartum care but also vertically in terms of clinical risk and acuity or need for complex medical care. This is a key feature for provision of care as well as the experience of care, in recognition of the fact that clients' experiences of referrals to different but intimately related services within the same facility can be frustrating, and ultimately can deter clients from using services.

\section{Applying the updated quality of care framework in Northern Nigeria: A case}

\section{study}

The updated framework informed the development of a QoC strategy paper and measurement tools for the Maternal, Newborn and Child Health $2(\mathrm{MNCH} 2)$ program in Northern Nigeria. The program aims to accelerate reductions in maternal, newborn, and child mortality by improving the quality, coverage, and demand for integrated $\mathrm{MNCH}$, routine immunization services, and healthy timing and spacing of pregnancy in six states in Northern Nigeria: Jigawa, Kaduna, Kano, Katsina, Yobe, and Zamfara $[19,20]$. MNCH2 brings together various program components on 
demand, supply, governance, evidence, advocacy, and accountability toward a common goal of making quality improvements.

The definitions of each QoC element in the framework were adapted specifically for use in this setting (Table 1) following a consultation in Kano in October 2014 with the $\mathrm{MNCH} 2$ teams. Key $\mathrm{MNCH} 2$ activities that will contribute toward achieving quality for each element of care were highlighted, and indicators and data sources were identified. The framework has underpinned the design of an assessment tool to collect QoC information across comprehensive, basic, and maternity health services. The tool measures different elements of quality and presents an opportunity to discuss QoC improvement strategies with healthcare providers. Findings are presented in an easy to interpret scorecard format to facilitate rapid action directed at QoC improvements. The tool also provides evidence to support planning and budgeting processes where further program and government investments are required to improve quality.

The QoC assessment tool includes approximately 5-10 indicators per element in the updated framework. Table 2 shows the types of indicators being monitored under each element and corresponding baseline data within the provision of care dimension.

Data were collected between April and August 2015 from a total of 231 health facilities (68 comprehensive and 156 basic EmONC facilities) across six northern states to obtain baseline data for the program. Data were collected by state and local government area staff and supervised by MNCH2 staff. Findings for each QoC 
element per state are presented in Figures 2-4. Data from 231 sampled BEmONC and CEmONC facilities in six northern Nigerian states showed that only $35 \%-47 \%$ of facilities met minimum quality standards in infrastructure. Standards for human resources performed better with 49\%-73\% reaching minimum standards. Although the QoC results were more favorable in some states than others, the findings, when fed back to service providers, sparked conversations and the development of action plans on how to improve QoC over the subsequent quarter.

Immediate next steps include $\mathrm{MNCH} 2$ working with a total of 954 facilities (six facilities per local government area) in each of the six northern states over the period 2014-2019. The QoC assessment tool will be used to gather data in all 954 facilities using mobile phones to monitor progress, influence decision-making, and inform systemic actions to improve quality. To validate data accuracy from mobile phones as well as QoC changes, in person spot checks using the tool will be administered to $5 \%$ of randomly selected $\mathrm{MNCH} 2$-supported facilities every quarter.

The QoC dimension of care related to experience of care is not covered in Table 2 as different methods have been used to capture data on this dimension of quality and data analysis is still underway. A client satisfaction survey has been designed (see Appendix 1) to collect data on aspects of QoC that affect patient experience on availability of services and clinical effectiveness. These interviews explore cognition, respect, dignity, and equity elements from a client's perspective. For example, it examines whether information on services and treatment are communicated in a way in which women understand their options and feel respected. 
Initial findings point to high satisfaction rates (over $90 \%$ ) indicating the complexity of evaluating the experience of care and the need to interview women who both use and do not use RMNCH services. The program is thus also using other complementary tools to collect data on perceptions of QoC from both service users and nonusers including:

- Facility health committees: directly reporting on patients' and nonpatients' experiences anonymously.

- Community scorecards: collecting community views on patients' and nonpatients' experience, including questions on attitudes and friendliness of the health staff.

Evidence from healthcare providers and users will inform a multifaceted response to QoC within the health system. It will also be used to strengthen accountability for improved $\mathrm{RMNCH}$ outcomes by targeting information to decision-makers and influencers from the community through to leaders at policy level who are able to unlock systemic QoC bottlenecks. The framework in this setting is more than a monitoring tool; it is a blueprint for action and is being used to stimulate performance improvements.

\section{A need for better quality of care tracking at facilities in the post-2015} measurement framework

Clearly, QoC needs to be addressed to complete the agenda of improved survival for women and newborns. Currently it seems difficult in many settings to capture information about quality at national or subnational level at frequent enough intervals to provide actionable data over time. Even tracer indicators are hard to come by, as 
surveys and health management information system reports focus on coverage rather than quality. Although EmONC needs assessments provide glimpses into QoC, the irregular and long intervals (about $5-10$ years) between surveys make it difficult to respond to quality issues in a timely manner in the absence of regular alternative data capture and feedback efforts.

The very complexity of defining "quality care" in its broadest sense has held us back from assessing progress, but by defining quality by its component parts we can make it simpler and more amenable to transparency in monitoring. For some of the elements of the framework, the methodologies for collecting data are already available and others are being rapidly developed. For example, EmONC needs assessments made with mobile phone technology are cheaper to conduct (though less robust). They can evaluate infrastructure, supplies, human resources, and signal functionality. Quality of institutional care is a new and simple approach to collecting data on some of the key elements of QoC where data can be collected, analyzed, and displayed quickly enough to inform service providers and relevant decision makers [21]. The method was designed by the Evidence for Action team to improve access to actionable information to improve QoC. Client satisfaction surveys have also been conducted sporadically and Demographic Health Survey assessments include questions that can be used to indicate quality [22]. The respectful care movement, spearheaded by the White Ribbon Alliance, WHO, and some healthcare professional associations (such as the International Confederation of Midwives, FIGO, and the international pediatric associations) are beginning to develop indicators that could be useful to record women's experience of care. 
Facility monitoring and tracking were developed by the Averting Maternal Death and Disability program and the original process indicators were based on signal functions. Tracking whether a facility has carried out a signal function intervention within the last 3 months is crucial, and some countries, including Bangladesh and Haiti have moved to a continuous EmONC monitoring system, rather than periodic EmONC surveys. However, the elements suggested by the updated QoC framework give a more comprehensive view of quality in the management of both normal and complicated births and these data supplement and augment the signal functions. They reflect the "nonmedical" nature of normal pregnancy and childbirth and allow interventions to be put in context and assessed as to their appropriateness, not just their availability.

Consensus in the measurement of $\mathrm{QoC}$ in $\mathrm{MNH}$ is needed so that is can be embedded into the SDGs. The updated framework being applied in the Nigeria case study could be the convening point around which a multidimensional index can be developed using evidence that stems from experience and a growing need to ensure use of hard data to drive meaningful changes in quality. At the start of the MDG period, the majority of low- and middle-income countries had limited data on maternal mortality, and yet the measure - the maternal mortality ratio—was rightly included in the MDG accountability framework. We now have a full series of data for survival outcomes. We should aspire to develop systems to assure availability of comprehensive and transparent data on quality of all aspects of care.

\section{Going further toward quality of care certification and quality marking}


In addition to measurement and indicators in the SDG framework, it is our view that it is time for new QoC tracking data to be collected and used to support a formal certification system and so institutionalize the transparent ongoing monitoring of facility and service quality to enable quality improvements.

As suggested in the recent set of standards proposed by FIGO and partners [23], international and national agencies could work together to develop a cadre of professionals to conduct site visits to monitor this process. Formal testing of models is needed. Evidence is especially needed on the costs of achieving and sustaining, gains in access and utilization, clinical outcomes, sustainability within different health care sectors, and the institutionalization of quality standards within pre-service and in-service training and career progression criteria.

Certification offers a practical and concrete opportunity to drive quality standards up and reward good performance. It also offers a mechanism to strengthen accountability. QoC is an important link between improved access to services and improved outcomes. Certification could be the means to stimulate the quality improvements needed to reduce preventable maternal and newborn death. As we say goodbye to the MDGs, now would be an opportune time to introduce a certification mechanism to drive quality improvement in the era of the SDGs. There are plenty of examples of successful certification within health care and across other sectors, where it is used to support improvement in standards, and from which we can learn in our quest to reduce the number of preventable maternal and newborn deaths over the next 25 years [24-30]. 


\section{Acknowledgments}

We would like to thank the following individuals for their work on collating, analyzing, and using quality of care data under MNCH2: Abba Umar, Eleanor Brown, Nkemdilim Ene, Dayyabu Yusuf, Zainab Muhammad, Hamzah Ahmed, Abdullahi Sule, Yusuf Lawal, Ali Alkali, Amina Ladan, Binta Kabir, Dije Abdul, Ester Kakn Omar, Hannatu Mohammed, and Aishatu Abdu Saleh.

\section{Conflict of interest}

The authors have no conflicts of interest. 


\section{References}

[1] van den Broek N, Lewis G, Mathai M. Guest editors' choice. BJOG 2014;121(Suppl 4):2-3

[2] Godlee F. Effective, safe, and a good patient experience. BMJ. 2009;339:b4346. http://www.bmj.com/content/339/bmj.b4346

[3] Tuncalp Ö, Were WM, MacLennan C, Oladapo OT, Gülmezoglu AM, Bahl R, et al. Quality of care for pregnant women and newborns-the WHO vision. BJOG 2015;122(8):1045-9.

[4] Raven $\mathrm{JH}$, Tolhurst RJ, Tang S, van den Broek N. What is quality in maternal and neonatal health care? Midwifery 2012;28(5):e676-83.

[5] Austin A, Langer A, Salam RA, Lassi ZS, Das JK, Bhutta ZA. Approaches to improve the quality of maternal and newborn health care: an overview of the evidence. Reprod Health 2014;11(Suppl 2):S1.

[6] Brown S. Foreword. BJOG 2014;121(Suppl 4):1.

[7] Hulton L, Matthews Z, Stones RW. A framework for the evaluation of quality of care in maternity services. Southampton: University of Southampton; 2000. http://core.ac.uk/download/pdf/29877.pdf[10] UNICEF, WHO, UNFPA. Guidelines for monitoring the availability and use of obstetric services. New York: UNICEF; 1997. http://www.childinfo.org/files/maternal_mortality_finalgui.pdf [11] Maine D, Rosenfield A. The AMDD program: history, focus and structure. Int J Gynecol Obstet 2001;74(2):99-103.

[12] White Ribbon Alliance. Respectful Maternity Care: The Universal Rights of Childbearing Women. London:WRA; 2011 http://whiteribbonalliance.org/wpcontent/uploads/2013/10/Final_RMC_Charter.pdf 
[13] Renfrew MJ, McFadden A, Bastos MH, Campbell J, Channon AA, Cheung NF, et al. Midwifery and quality care: findings from a new evidence-informed framework for maternal and newborn care. Lancet 2014;384(9948):1129-45.

[14] van Lerberghe W, Matthews Z, Achadi E, Ancona C, Campbell J, Channon A, et

al. Country experience with strengthening of health systems and deployment of midwives in countries with high maternal mortality. Lancet 2014;384(9949):1215-25. [15] Hulton LA, Matthews Z, Stones RW. Applying a framework for assessing the quality of maternal health services in urban India. Soc Sci Med 2007;64(10):208395.

[16] Ministry of Health and Population Nepal. Monitoring Quality of Care in Maternity Services, Kathmandu: Department of Health Services; 2004.

[17] Commission on Information and Accountability for Women's and Children's Health. Keeping Promises, Measuring Results. Geneva: WHO; 2011.

http://www.who.int/topics/millennium development goals/accountability commission /Commission Report advance copy.pdf

[18] UNFPA. The State of the World's Midwifery 2014: A Universal Pathway. A Woman's Right to Health. New York: United Nations Population Fund; 2014. http://www.unfpa.org/sowmy

[19] MNCH2. Our Partners in Brief. http://mnch2.aawasymbiotic.com/partners/. Published 2015. Accessed June 30, 2015. [20] MNCH2. Quality of Care Strategy: Maternal, Newborn and Child Health 2; 2014. [21] MamaYe. Factsheet. Quality of institutional care: rapid data informing action. http://www.mamaye.org/sites/default/files/evidence/Factsheet\%20on\%20QulC.pdf. Published 2014. Accessed August 18, 2015. 
[22] DHS Program website. SPA Overview. http://dhsprogram.com/What-WeDo/Survey-Types/SPA.cfm. Accessed August 19, 2015.

[23] Lalonde AB, Miller S. Mother-baby friendly birthing facilities initiative. Int $J$ Gynecol Obstet 2015;128(2):93-4.

[24] National Institute for Health and Care Excellence. NICE Accreditation. https://www.nice.org.uk/about/what-we-do/accreditation. Published 2014. Accessed September 25, 2015.

[25] Sharma, KD. Implementing quality process in public sector hospitals in India: the journey begins. Indian J Community Med 2012;37(3):150-2.

[26] Skills for Care website. The Care Certificate Framework: Guidance Document. http://www.skillsforcare.org.uk/Standards/Care-Certificate/Care-Certificate.aspx. Published February, 2015. Accessed September 14, 2015. [27] Johnson AM, Goldstein LB, Bennett P, O'Brien EC, Rosamond WD; investigators of the Registry of the North Carolina Stroke Care Collaborative. Compliance with acute stroke care quality measures in hospitals with and without primary stroke center certification: the North Carolina Stroke Care Collaborative. J Am Heart Assoc 2014;3(2):e000423.

[28] Kassa H, Silverman GS, Baroudi K. Effect of a manager training and certification program on food safety and hygiene in food service operations. Environ Health Insights 2010;4:13-20.

[29] van Dam J, Junginger M, Faaij AP. From the global efforts on certification of bioenergy towards an integrated approach based on sustainable land use planning. Renewable and Sustainable Energy Reviews 2010;14(9): 2445-72. [30] Agnew DJ, Gutiérrez NL, Stern-Pirlot A, Hoggarth DD. The MSC experience: developing an operational certification standard and a market incentive to improve 
fishery sustainability. ICES J Mar Sci 2013.

http://icesjms.oxfordjournals.org/content/early/2013/07/27/icesjms.fst091.full 
Box 1

WHO's framework for quality of care.

WHO has recently developed a framework for the QoC of pregnant women and newborns in health facilities based on the structural components of a health system. This framework is based on and very similar to the original Hulton et al. [7] framework and was recently endorsed by an expert meeting held June 3-4, 2015. In WHO's version, the "process" of QoC takes place along two interlinked dimensions - the provision and experience of care-and consists of eight domains of quality care. Three of these domains characterize provision of care: evidence based practices for routine and emergency care; actionable information systems; and functional referral systems. Those that characterize the experience of care include effective communication; respect and dignity; and social and emotional support. Those domains that cut across both dimensions include competent and motivated human resources and essential physical resources [3, p.3]. 
Table 1

Updated quality of care framework.

Element of Provision of care
quality of
care

1. Human MNH services are provided by

resources

2.

Infrastructure designed, built, cleaned, and maintained to provide quality, cost-effective MNCH care and are responsive to need and provide a safe, supportive, and functional environment.

3. Equipment, $\mathrm{MNCH}$ services have a reliable supplies and and responsive supply of medicines appropriate equipment, supplies, and essential medicines that are properly stored, maintained, and used by trained and skilled staff, to ensure the provision of quality $\mathrm{MNCH}$ care.

$\begin{array}{ll}\text { 4. Clinical } & \mathrm{MNCH} \text { care is provided in } \\ \text { practice } & \text { accordance with internationally }\end{array}$ recognized, evidence-based good practice for improving $\mathrm{MNCH}$ outcomes.

5. Respect, cognition, and equity

6. Networks of care and integration
All points on the $\mathrm{MNCH}$ continuum of care are connected so that referral is effective and timely, and service providers communicate with each other between services and between levels of care. This will ensure optimal recognition, management,
Women and families express confidence in the level of human resources available for the care of themselves and/or their family members in terms of competency, number, and gender of staff. Women and families express confidence in the level of physical resources available for the care of themselves and/or their family members in terms of physical infrastructure and the health facility environment.

Women and families report no shortages of equipment, drugs, and supplies that, from their perspective, influenced the quality of care they received.

$\mathrm{N} / \mathrm{A}$

Women and families, regardless of education, economic status, place of residence, or other sociocultural factors, report feeling well informed, emotionally supported, and receive culturally sensitive, respectful care from all levels of health staff.
Women and their families understand where they should go and why.
Why this element of quality of care is important for maternal, newborn, and child outcomes

Optimal quality care only provided with a workforce that has strong capacity and supporting structures.

Facilities designed, maintained, and managed so quality $\mathrm{MNCH}$ services are provided.

Clients' experience and likelihood of using a facility is affected by service location, design, cleanliness, and state of maintenance.

Systems in place for procurement, pricing, availability, storage, and maintenance of equipment, supplies, and medicines to maintain the effective delivery of $\mathrm{MNCH}$ care. Clients' experience of care is influenced by her impression of the resources allocated to her care.

For women and their children to have access to care that is informed by internationally recognised good practice and uses appropriate technologies.

Clients' experience of care or perception of quality can affect their future care-seeking behaviour and that of their community.

Poor provider-client information exchange can prevent the communication of important information, which may influence the outcome.

Equity relates to whether women and their children have equal access to $\mathrm{MNCH}$ services and quality of care is provided at the same standard regardless of their socioeconomic, cultural, or religious background.

$\mathrm{MNCH}$ services must be effectively integrated and referral to, within, and between services is coordinated and effective.

Networks of care include not only those between health professionals but networks at community level that enable women and children to access care in a timely manner. 
referral and follow-up of routine conditions, complications, and emergencies.

\section{Evidence} and information

$\mathrm{MNCH}$ services have information systems providing reliable, timely, and easily accessible data and information. Healthcare planners, managers, and healthcare professionals can use this information to make evidence-based and timely decisions for strengthening quality of $\mathrm{MNCH}$ care.
$\mathrm{MNCH}$ managers have information systems providing reliable, timely, and easily accessible data and information. Communities and clients can access and use this information to better manage their health, monitor how their local health services are performing, and hold the health system accountable to providing quality care.
To generate and communicate accurate information to plan, implement, manage, monitor, and evaluate $\mathrm{MNCH}$ activities and their outcomes, which will support the quality improvement cycle.

Decision-makers cannot make rational, timely, and informed decisions in the absence of the right information in the right format at the right time.

Users, communities, and their representatives have a right to information to strengthen accountability and make decisions about their own health and use of services. 
Table 2

Northern Nigeria case study: Baseline data ${ }^{a}$ for selected measurable indicators for each aspect of care.

\begin{tabular}{|c|c|c|}
\hline Element of quality of care & Selected provision of care indicators being tracked at facility level & $\begin{array}{l}\text { Provision of care baseline. } \\
\text { Average calculated across six northern } \\
\text { Nigeria states (231 CEmONC and } \\
\text { BEmONC facilities) }\end{array}$ \\
\hline 1. Human resources & $\begin{array}{l}\text { \% of facilities with at least two trained providers available at all times in the last } 24 \text { hours } \\
\text { to perform normal delivery } \\
\% \text { of facilities with at least one trained provider available at all times in the last } 24 \text { hours } \\
\text { to perform newborn resuscitation with a bag and mask }\end{array}$ & $54 \%$ \\
\hline 2. Infrastructure & $\begin{array}{l}\% \text { of facilities with a sink, tap, running water, and soap/alcohol rub in the last } 24 \text { hours } \\
\% \text { of facilities with an easily accessible and functional toilet for women in labor }\end{array}$ & $\begin{array}{l}43 \% \\
63 \% \\
\end{array}$ \\
\hline $\begin{array}{l}\text { 3. Equipment, supplies, and } \\
\text { medicines }\end{array}$ & $\begin{array}{l}\% \text { of facilities with availability of a delivery kit (two artery forceps, cord scissors, cord } \\
\text { clamp/episiotomy scissors, and mucus extractor) } \\
\% \text { of facilities with availability of personal protective wear (surgical gloves, goggles, boots, } \\
\text { aprons, face masks) } \\
\% \text { of facilities with availability of magnesium sulfate }\end{array}$ & $\begin{array}{l}70 \% \\
53 \% \\
45 \%\end{array}$ \\
\hline 4. Clinical practice & $\begin{array}{l}\text { \% of facilities with providers who routinely used the partograph to monitor labor over the } \\
\text { past month } \\
\% \text { of facilities with providers who routinely perform manual removal of placenta over the } \\
\text { past month }\end{array}$ & $\begin{array}{l}49 \% \\
84 \%\end{array}$ \\
\hline $\begin{array}{l}\text { 5. Respect, cognition, and } \\
\text { equity }\end{array}$ & $\begin{array}{l}\text { \% of facilities with a clearly marked suggestion/complaints box easily accessible to the } \\
\text { public } \\
\% \text { of facilities with availability of privacy for women delivering (e.g. separate room, } \\
\text { curtain/divider around bed, curtains on windows) }\end{array}$ & $22 \%$ \\
\hline $\begin{array}{l}\text { 6. Networks of care and } \\
\text { integration }\end{array}$ & $\begin{array}{l}\text { \% of facilities stating emergency transportation was arranged for the last woman who was } \\
\text { referred to a higher level facility } \\
\text { \%facilities in the last quarter with providers undertaking any outreach/awareness } \\
\text { activities }\end{array}$ & $\begin{array}{l}38 \% \\
71 \%\end{array}$ \\
\hline
\end{tabular}


${ }^{a}$ Baseline data were collected from 231 facilities across six states from April to Aug 2015 (Jigawa $n=45, K a d u n a ~ n=26, K a n o ~ n=54, K a t s i n a ~ n=42, ~ Y o b e ~ n=34$,

Zamfara $\mathrm{n}=30$ ). 


\section{Appendix 1}

Client satisfaction tool.

\begin{tabular}{|l|l|l|l|}
\hline Reported satisfaction with health services & $\begin{array}{c}\% \\
\text { agree/strongly } \\
\text { agree }\end{array}$ & \% neutral & $\begin{array}{c}\text { \% disagree/strongly } \\
\text { disagree }\end{array}$ \\
\hline Main reason for visit dealt with satisfactorily & & & \\
\hline I was given sufficient privacy & & & \\
\hline I was given enough time for my needs & & & \\
\hline The clinic was clean & & & \\
\hline Composite score $(\%$ agreeing) & & & \\
\hline
\end{tabular}

\begin{tabular}{|l|l|l|l|}
\hline Reported satisfaction with health staff attitudes & $\begin{array}{c}\% \\
\text { agree/strongly } \\
\text { agree }\end{array}$ & \% neutral & $\begin{array}{c}\text { \% disagree/strongly } \\
\text { disagree }\end{array}$ \\
\hline I was made to feel welcome by health staff & & & \\
\hline $\begin{array}{l}\text { The health staff talked to me in a way that I } \\
\text { can understand }\end{array}$ & & & \\
\hline The health staff talked to me with respect & & & \\
\hline The health staff talked to me with kindness & & & \\
\hline Total score for indicator & & & \\
\hline
\end{tabular}

